UDC: $316.7(497.11)$

DOI: https://doi.org/10.18485/hispserb.2019.2.ch11

\author{
Vesna Dickov ${ }^{1}$ \\ Universidad de Belgrado \\ Serbia
}

\title{
UNA MIRADA SOBRE LAS RELIGIONES PRECOLOMBINAS: EL PUNTO DE VISTA DE LOS LECTORES SERBIOS
}

\begin{abstract}
Resumen
El propósito del presente trabajo yace en investigar un aspecto peculiar de la recepción de las religiones precolombinas en Serbia, que consta en agrupar y presentar críticamente, respetando el criterio cronológico, los estudios científicos que tratan la cuestión del panteón indígena, así como las compilaciones sobre la misma cuestión, estudios y compilaciones realizados por autores serbios e impresos en ediciones especiales en el idioma serbio. El enfoque está puesto en explorar los libros dedicados a las religiones de los principales pueblos autóctonos de Hispanoamérica (los mayas, los aztecas y los incas), elaborados por diferentes autores y editores de Serbia (antropólogos, profesores de literatura, investigadores, periodistas, críticos). Se presta atención a todos los parámetros de este proceso de recepción (principales participantes directos, casas editoriales, dinámica de desarrollo, tiradas) con el fin de obtener una imagen tan clara y completa como sea posible sobre las propiedades del horizonte de expectativas de los lectores serbios (formación inicial, cambios, modificaciones, ampliaciones) en cuanto a la percepción y el recibimiento de las religiones precolombinas que se llevaron a cabo a finales del siglo XX y principios del siglo XXI. Durante un periodo de veintidós años (1988-2010), gracias a los
\end{abstract}

\footnotetext{
${ }^{1}$ vesna.dickov@fil.bg.ac.rs
} 
editores de Belgrado, aparecieron siete libros en varias tiradas (500-3000 copias), resultado del trabajo de dos autores (Aleksandar Bošković, Jelena Galović) y dos editores (Miodrag Šijaković, Milan Balinda). Debido a este exitoso proceso de recepción, los lectores serbios tuvieron la oportunidad, aunque con retraso, de conocer los conceptos básicos de las religiones de los pueblos precolombinos más importantes, especialmente los mayas y aztecas, de modo que su horizonte de expectativas está bien formado y preparado para expandirse en el futuro.

Palabras clave: religiones precolombinas, los incas, los mayas, los aztecas, recepción.

\section{Introducción}

Las civilizaciones precolombinas forman parte integral de la cultura hispanoamericana en general. A fin de comprender tanto la esencia como las variadas manifestaciones de las culturas pertenecientes a los pueblos autóctonos que poblaban el suelo americano antes de la colonización española, así como las similitudes y las diferencias entre las organizaciones sociales de esas comunidades antiguas, es indispensable entender (para no repetir comprender), sobre todo, sus religiones, teniendo en cuenta la singularidad y complejidad del concepto de religión que se mantenía en esas culturas, ya que la religión para los pueblos prehispánicos representaba no solamente sus creencias y espiritualidad sino también sus mitos y sus rituales, es decir, su entera cosmogonía.

En la época precolombina, las creaciones literarias aparecían dentro del marco de ciertas estructuras social-religiosas y tenían principalmente funciones utilitarias: el almacenamiento de datos, la celebración de los dioses, la interpretación del origen del hombre en la tierra, etc. (Pavlović-Samurović 1993: 13). Por ello, durante el proceso de la recepción de las literaturas prehispánicas, los lectores serbios obtuvieron también impresiones sobre las religiones precolombinas². Aunque esos contactos tenían un carácter indirecto y parcial, contribuyeron en gran

\footnotetext{
${ }^{2}$ La recepción de las literaturas prehispánicas en Serbia comenzó en el año 1961 con la publicación de las antologías Poezija Acteka (Poesía de los Aztecas) y Poezija Inka (Poesía de los Incas) preparadas por los editores serbios Nikola Trajković y Miodrag Šijaković respectivamente; el libro en prosa Kecalkoatl - pernata zmija (Quetzalcoatl) del autor mexicano José López-Portillo apareció traducido al serbio en 1977, mientras que dos piezas de teatro, pertenecientes a los pueblos de los mayas y los incas, se editaron en el idioma serbio unidos en un solo libro, publicado en el 1982 bajo el título Rabinal Aći. Apu Oljantaj (Rabinal Achí. Apu Ollantay).
} 
medida a la preparación del horizonte de expectativas de los lectores en Serbia con respeto a la percepción de las religiones de los antiguos pueblos indígenas (Dickov 2012, 2013). Esa visión inicial fue ampliada considerablemente a finales del siglo XX y comienzos del siglo XXI, cuando aparecieron libros escritos por autores serbios e impresos en serbio, dedicados por completo a los temas religiosos de los principales pueblos amerindios (los aztecas, los mayas y los incas).

Nuestro propósito es investigar el papel que dichas obras tuvieron en la modificación del horizonte de expectativas de los lectores en Serbia. Con este objetivo, los libros en cuestión serán presentados de una manera crítica y analítica, tomando en consideración el criterio cronológico de su aparición. Se prestará especial atención a sus autores y editores, así como a otros elementos relevantes para ese proceso de recepción (las editoriales, el ritmo de publicación, las tiradas).

\section{El siglo $X X$}

Las religiones prehispánicas empezaron a despertar un interés serio y profundo en Serbia durante la segunda mitad del siglo XX, cuando fueron publicados los primeros libros de autores serbios sobre las religiones vigentes en los tres mayores imperios precolombinos (el maya, el azteca y el inca). El profesor Aleksandar Bošković, antropólogo, que durante sus estudios de posgrado permaneció varios meses en Guatemala, escribió dos libros dedicados a la religión maya.

El primer libro de Bošković La religión de los mayas (Majanska religija) fue publicado en el año 1988 en Belgrado por la editorial Opus, en una tirada de 1000 ejemplares. Esta obra es el resultado de una investigación larga y compleja, que el autor llevó a cabo con el objetivo de desmitificar la civilización de los antiguos mayas. Bošković (1988: 10) quiso mostrar que la evolución de los mayas corresponde en muchos aspectos a los patrones culturales característicos de la evolución de todas las comunidades humanas. Por ejemplo: el calendario de los mayas se parece, por el interés especial que ocupa el movimiento de Venus, al antiguo calendario chino; la organización feudal maya es similar a la de los pequeños estados medievales europeos; los pequeños estados mayas a menudo combatían unos con otros, igual que los estados independientes de la antigua Grecia o Sumeria; los códices que los mayas escribían sobre la piel de animal, fueron conocidos también en Asia del Sur. Por otro lado, Bošković (1988: 10-11) destaca los siguientes rasgos específicos de los mayas, por los cuales ese pueblo indígena se distingue de otras 
civilizaciones antiguas: algunos criterios estéticos (el cráneo deformado, la leucoma), la gran atención prestada al comercio, el concepto peculiar del sacrificio humano, el carácter (casi siempre) ritual del juego con pelota de goma, la agricultura basada mayormente en el cultivo de maíz, la combinación de dos calendarios (el aproximativo de 365 días y el calendario santo de 260 días), etc.

La religión maya es percibida por Aleksandar Bošković como un sistema simbólico de interacción entre el hombre y la naturaleza o, mejor dicho, su medio ambiente determinado por las instituciones estatales y circunstancias varias (políticas, sociales, económicas). Por lo tanto, el libro La religión de los mayas está basado en numerosos resultados de investigaciones multidisciplinarias (antropológicas, arqueológicas, etnográficas, etnológicas, epigráficas, históricas, lingüísticas, literarias, iconográficas), que el autor utilizó a fin de profundizar en los conocimientos existentes sobre la religión maya desde un diferente punto de vista.

La composición del libro La religión de los mayas consta de siete capítulos. El primer capítulo es de carácter introductorio y comprende un panorama de los estudios realizados desde el siglo XVI (Bartolomé de las Casas, Bernardino de Sahagún, Diego de Landa) hasta el siglo XX (Alfred Tozzer, Eduard Seler, Richard Adams, David Stuart, Nicholas Hellmuth), así como varias teorías sobre el origen de los mayas (descendientes de los chinos, egipcios, tribus perdidas, visitantes del espacio, etc.). El segundo capítulo está dedicado a las religiones de los pueblos precolombinos de Mesoamérica, sobre todo los olmecas, los toltecas y los aztecas. En el tercer capítulo, el autor se ocupa de la civilización maya en general, con especial énfasis en su calendario y astronomía, mientras que en el cuarto capítulo escribe sobre los principales dioses y diosas mayas. El quinto capítulo contiene la interpretación de la cosmología de los mayas y su religión. En el sexto capítulo, Bošković analiza Popol Vuh, el libro sagrado de los mayas-quichés, junto con el mito de los mellizos heroicos divinos. El último (séptimo) capítulo trata algunas de las religiones precolombinas que han sobrevivido hasta la época contemporánea (por ejemplo, la religión del pueblo tzotzil) y ofrece una reseña del análisis de Eric Wolf sobre el mito de la Virgen de Guadalupe.

Teniendo en cuenta críticamente el punto de vista de la antropología social-cultural, las opiniones de numerosos especialistas y científicos, sobre todo las de Miguel León-Portilla, así como los resultados de las investigaciones realizadas según el método del "enfoque histórico directo" (direct historical approach) utilizado por Henry Nicholson, que comprende la percepción de los datos requeridos en el 
contexto global combinándolos con el uso de datos sobre las culturas autóctonas más conocidas (especialmente la náhuatl), y, también, tomando en consideración los resultados obtenidos gracias al "método maya" proclamado por Nicholas Hellmuth, que se basa únicamente en el estudio llevado a cabo dentro del marco de la cultura maya, Bošković (1988: 23-24) determina el concepto de la "religión" como un sistema de manifestaciones simbólicas que sirve para hacer posible la comunicación del hombre con otros seres humanos y el mundo que le rodea. En este sentido, "la religión maya" se define como un sistema de representaciones simbólicas que circulaban a lo largo del Período Clásico (250 d.C. - 900 d.C.), marcado por la civilización desarrollada en la ciudad de Teotihuacán, y durante el Período Posclásico, que llegó a su cumbre alrededor del año 1000 d.C. cuando las ciudades y los famosos centros ceremoniales de Yucatán (Chichén Itzá, Ushmal, Kabáh, Tankah, etc.) experimentaron su mayor auge.

Dos años después, salió el libro La religión y la cultura de los mayas (Religija i kultura Maja) también de Aleksandar Bošković, publicado por la editora Kodeks de Belgrado. El autor explica en la nota introductoria que el gran interés mostrado tanto de los lectores como de los críticos serbios por su libro anterior La religión de los mayas, provocó la necesidad de una nueva edición, ampliada con datos actualizados, varias ilustraciones y fotos, en la que se presta mayor atención al contexto cultural general. En ambas obras, Bošković (1990: 9) parte del supuesto de que es posible acercarse a los pueblos de climas lejanos y culturas diferentes, ya que la comprensión del otro y de lo diferente representa una condición previa e indispensable para entendernos a nosotros mismos. El libro La religión y la cultura de los mayas fue impreso en una tirada de 2000 ejemplares.

A la vez, aparecieron dos compilaciones - La mitología y la religión de los aztecas (Mitologija i religija Asteka) y La mitología y la religión de los incas (Mitologija i religija Inka) - preparadas por el editor Miodrag Šijaković (1990a, 1990b), crítico literario, que fueron publicadas en Belgrado el mismo año (1990) por la editorial Dečja knjiga e impresas en una tirada de 3000 ejemplares cada una. Las ediciones mencionadas ofrecen a los lectores serbios una selección de textos sobre las tradiciones religiosas de los antiguos aztecas e incas, junto con varias leyendas y mitos de esos dos pueblos precolombinos. Ambos libros contienen textos de carácter suplementario (prólogo, epílogo, nota), preparados por el coordinador con el objetivo de facilitar su acercamiento a nuestros lectores.

En el caso de la compilación La mitología y la religión de los aztecas, Šijaković escribió un prólogo dividido en siete partes, cuyos 
títulos ya anuncian sus correspondientes contenidos: 1) "La visión general" contiene un panorama del contexto histórico y social del mundo azteca; 2) "Los mitos sobre la creación del mundo" explica brevemente la periodización de épocas según la mitología azteca; 3) "El panteón azteca" intenta presentar lo más precisamente posible los principales dioses de los antiguos aztecas; 4) "Otras deidades" contiene la interpretación de significado de numerosas deidades secundarias y héroes de la cultura azteca que, en la mayoría de los casos, tenían carácter solar; 5) "El calendario" valora el calendario azteca, junto con el cronoscopio, para el cual el autor señala que, gracias a las traducciones en serbio, también está disponible para los lectores serbios; 6) "El clero" ofrece una corta descripción de la vocación sacerdotal entre los antiguos aztecas (las escuelas para la educación, el papel que tuvieron en la sociedad, los rituales de sacrificio); 7) "Conclusión" contiene las consideraciones finales sobre los aztecas, como el pueblo más religioso en el mundo prehispánico. Al final del prólogo, el autor destaca que la religión y la mitología de los antiguos aztecas aunque, por un lado, son bastante sencillas, teniendo en cuenta su formación basada en los fenómenos astrales, por otro lado, se caracterizan por el politeísmo y el dualismo, con elementos de animismo y totemismo; un gran número de los dioses, semidioses y héroes legendarios proviene de la estructura de la sociedad azteca, reflejando el papel del hombre como un ser débil e impotente frente a las deidades y el orden del universo eternos, de modo que el mundo en que el hombre permanece y vive, al ser imperfecto, está condenado incondicionalmente a la destrucción inevitable (Šijaković 1990a: 16-17).

El libro La mitología y la religión de los aztecas está compuesto de dos partes: "Los mitos y las leyendas" que comprende quince textos provenientes de la tradición popular (11 mitos y 4 leyendas) sobre el mundo azteca (la creación del mundo, el buceo, los volcanes, las campañas militares, los aliados, las costumbres, la muerte, etc.) y "La segunda parte" que contiene tres extractos de los libros dedicados a la religión y la mitología de los aztecas ("El mito sobre Quetzalcóatl", "Comiendo a dios en aztecas", "El dominio de los aztecas"). Al final del libro se encuentra "La nota" con los datos sobre las fuentes y las traducciones utilizadas.

Para la compilación La mitología y la religión de los incas, el editor Miodrag Šijaković escribió un epílogo corto a fin de presentar a los lectores serbios algunos de los rasgos más importantes de la cultura incaica (su origen, períodos históricos, principales soberanos, deidades primordiales, tradición oral, leyendas sobre el primer Inca). En cuanto a la religión de los incas, Šijaković (1990b: 137-138) dice que la religión incaica oficial, la de 
los soberanos, se distinguía considerablemente de la religión de las masas populares, que tenían sus propios cultos presentados en forma de objetos antropomorfos; por ello , las clases altas de la sociedad incaica adoraban a Viracocha, mientras que el pueblo veneraba - a través de diferentes ceremonias rituales - sus huacas o sacralidades específicas de toda clase (las cuevas, las montañas, los valles, los lagos, los ríos, los templos, las tumbas), es decir, todo lo que escapaba a la razón humana y tenía una forma inexplicable, mágica y maravillosa. El epílogo contiene, también, una advertencia del editor sobre las fuentes y las traducciones utilizadas, así como una breve descripción de la composición de la compilación, que abarca: once canciones en honor a Viracocha, el dios supremo de los incas; catorce mitos relevantes para la cultura y la civilización de ese pueblo indígena; siete capítulos de los Comentarios reales de los incas de Garcilaso de la Vega, el Inca; un segmento aparte que lleva el subtítulo "Los incas en la luz de la ciencia" y comprende tres extractos de libros dedicados a la civilización de los incas (su existencia hasta la conquista española, la organización social, el arte).

La contribución de las compilaciones La mitología y la religión de los aztecas y La mitología y la religión de los incas, preparadas por Miodrag Šijaković, al ensanchamiento del horizonte de expectativas de los lectores serbios tiene doble sentido: ambos libros proporcionan una perspectiva de los textos ya conocidos, pero de una manera más compleja que las anteriores, y, por otro lado, el hecho de que dichas compilaciones se basan únicamente en los materiales disponibles en las bibliotecas de Serbia, no sólo confirma adicionalmente la formación del horizonte previo, sino también implica las directrices posibles para sus futuras ampliaciones.

\section{El siglo XXI}

Jelena Galović, investigadora y profesora de literatura en la Universidad Nacional Autónoma de México (UNAM), es autora de dos libros sobre la religión y la espiritualidad de los pueblos autóctonos de México.

El libro Los grupos místico-espirituales de la actualidad, escrito por Jelena Galović en español, apareció primeramente en el año 2002 en México y luego fue traducido al serbio por la autora misma y publicado por la editora Srpski genealoški centar de Belgrado en el año 2005 bajo el título Mistično-duhovne grupe današnjeg vremena, en una tirada de 500 ejemplares. En esta obra, Jelena Galović presenta los resultados de la investigación que llevó a cabo durante muchos años con el objetivo 
de explorar varias escuelas, grupos, técnicas y maestros espirituales de la época contemporánea que existen en varios países del mundo, prestando especial atención a las prácticas desarrolladas en México. En la introducción, Galović (2005: 9) menciona los diferentes métodos (el comparativo, el creativo, la participación personal) que utilizó para explorar la relación entre las tradiciones orales y las tradiciones escritas que caracterizan diferentes enseñanzas espirituales. Su investigación estaba basada mayormente en la propia experiencia, vivida durante su estancia en grupos espirituales tradicionales. El método comparativo y el método creativo fueron aplicados para verificar la exactitud de la idea sobre la unidad interior, presente en diferentes tradiciones que - aunque estén separadas aparentemente - forman parte de una sola tradición o de una sola enseñanza espiritual, concebida con el objetivo de penetrar en el misterio de la existencia humana y el destino terrenal del hombre. Sin ningún deseo de agradar, complacer o persuadir a nadie, Jelena Galović (2005: 10-11) ofrece una mirada objetiva sobre varios grupos espirituales de la época contemporánea, que está fundada en el análisis exhaustivo de numerosos libros, textos sagrados y resultados de su investigación práctica, con el único objetivo de animar a los lectores creativos a que saquen sus propias conclusiones.

El libro Los grupos místico-espirituales de la actualidad está dividido en dos partes: en la primera parte, la autora presenta su propia experiencia, adquirida durante su permanencia en varios grupos y escuelas espirituales (los grupos de Gurdjieff, los grupos islámicos, los sufís, el de la Nueva Mexicanidad dirigido por Antonio Velasco Piña, los lamas tibetanos, Gran Fraternidad Universal, los hinduistas, los vaishnavas), poniendo un especial énfasis la Iglesia Católica, mientras que la segunda parte está dedicada a los concheros, es decir, a los grupos de danza ritual de México que tienen raíces mixtas, tanto prehispánicas como cristianas.

Jelena Galović participó durante dieciocho años (1983-2001) en las actividades de varios grupos de concheros, observando cómo su universo espiritual, compuesto de creencias, ceremonias y rituales, se manifestaba armoniosamente en la danza sagrada, acompañada de música. Miguel León-Portilla (2002: 5-6) destaca que la autora del libro Los grupos místico-espirituales de la actualidad fue la primera que escribió en detalle, objetivamente, con respeto y simpatía, sobre esas comunidades artísticas y tradicionales, utilizando tanto su propia experiencia práctica y testimonios de algunos concheros, como investigaciones de otros científicos (etnólogos, historiadores, antropólogos, folkloristas, 
psiquiatras). Tomando en consideración las características principales de los concheros (la fraternidad, la asociación, la comunidad), Galović intenta definir sus raíces provenientes de las culturas prehispánicas (los otomíes, los toltecas, los chichimecas, los aztecas) a fin de comprobar la continuidad en la existencia de esos grupos espirituales que, por un lado, siguen la tradición, y, por el otro, introducen nuevos rumbos modernos en su práctica. Un verdadero conchero debe estar dotado de muchas virtudes y amplios conocimientos de índole sincrética (cantar y bailar bien, conocer la tradición, curar, saber los rituales, participar en las vigilias, interpretar los sueños). La danza de los concheros está llena de símbolos y representa tanto los mitos indígenas sobre la creación del mundo como las escenas relacionadas con el dogma católico (la vida de Jesús Cristo, Virgen de Guadalupe o de varios santos). Para los concheros, la danza es lo mismo que la oración; uno llega a ser conchero sin ningún interés pecuniario, creyendo sinceramente que su actitud de conchero forma parte integral de su destino humano, cuya esencia consta en acercarse a la naturaleza y sus compatriotas. En realidad, al tratar el trabajo teórico y práctico de varios grupos espirituales de México, la autora se ocupó del origen indígena de las culturas de Mesoamérica, sin insistir en este tema (Galović 2005: 12).

Teniendo todo lo dicho en cuenta, se puede decir que el libro Los grupos místico-espirituales de la actualidad de Jelena Galović muestra que la tradición indígena todavía permanece viva y actual en México, manteniendo una espiritualidad lejana y desconocida para la mayoría de los lectores modernos (Benítez 2002: 384). Una conclusión similar se puede sacar en relación a los lectores de Serbia, por lo que el libro mencionado ha tenido gran importancia en la modificación cualitativa y el ensanchamiento de su horizonte de expectativas.

El segundo libro de Jelena Galović Los mayas, los aztecas y la tradición chamánica de México (Maje, Asteci i šamanska tradicija Meksika) fue publicado en Belgrado en el año 2008 por la editora Pešić i sinovi, en una tirada de 500 ejemplares. Esta obra es un conjunto de (48) ensayos que fueron escritos durante una década (1997-2007) con la intención de mostrar los intereses, las experiencias y los conocimientos de la autora sobre las antiguas culturas de México y sus rituales mágicos, poniendo de relieve aspectos por lo general desconocidos por los lectores (Galović 2008: 7).

El libro Los mayas, los aztecas y la tradición chamánica de México está dividido en tres partes. En la primera parte se ofrece un vasto panorama de los mayores pueblos precolombinos (los olmecas, los purépecha, los totonacas, los mixtecas, los zapotecas, los mayas, los toltecas, los aztecas) 
y sus culturas (religiones, dioses y rituales, literaturas, calendarios, música), basado en los estudios de varios renombrados especialistas así como en las investigaciones personales llevadas a cabo por la autora en diferentes sitios arqueológicos de México (Galović 2008: 15-125). Los ensayos particulares están dedicados a la religión de los mayas de Yucatán (Galović 2008: 76-80) y al principio supremo Tloque Nahuaque de los aztecas y los nahuas (Galović 2008: 87-92).

La segunda parte del libro Los mayas, los aztecas y la tradición chamánica de México está dedicada a las creencias y prácticas espirituales de varios pueblos mexicanos (los aztecas, los mayas, los huicholes), entre los cuales el chamanismo (el nagualismo) y los concheros permanecen actuales, en sincretismo con la herencia cristiana; también, en esta parte se describen las danzas rituales mexicanas más importantes que se realizan en los centros de máximo poder magnético (La Villa, Chalma, Amecameca, Los Remedios, Tlatelolco), se interpreta la esencia del chamanismo (la práctica, la literatura oral, la magia, el arte) y se presentan las experiencias personales de la autora, adquiridas durante su participación en los rituales de los huicholes (Galović 2008: 127207). Al tomar en consideración las posibilidades de aplicar las técnicas chamánicas en la época contemporánea, se presta especial atención a las investigaciones realizadas por Carlos Castaneda y sus libros, igual que a los encuentros personales que la autora tuvo con ese famoso antropólogo peruano, nacionalizado estadounidense (Galović 2008: 208-215).

La tercera parte del libro Los mayas, los aztecas y la tradición chamánica de México trata de la influencia del sustrato precolombino en la literatura hispanoamericana moderna (Galović 2008: 217-335). La autora interpreta la presencia de los mitos indígenas en las obras de algunos de los escritores más reconocidos de la América Latina del siglo XX. Carlos Fuentes, escritor mexicano, revive el mito de Quetzalcóatl, la figura principal de todas las culturas mesoamericanas (conocida bajo el nombre de Kukulkán en la mitología maya) en la segunda parte de su novela Terra Nostra, donde habla de la bajada de "La Serpiente Emplumada" en Mictlán, el lugar de la muerte. Quetzalcóatl aparece también en las Leyendas de Guatemala de Miguel Ángel Asturias, otro escritor guatemalteco, que en otra obra suya - la novela El Papa Verde - opone el mundo cruel y egoísta de los norteamericanos a las creencias y costumbres tradicionales de los mayas de Guatemala. Comala, el pueblo mítico, habitado por las almas muertas de la novela Pedro Páramo del escritor mexicano Juan Rulfo, no es más que una especie de Mictlán, el último de los nueve niveles del inframundo que, según las creencias de los antiguos aztecas, constituye el cosmos junto con 
el cielo y la tierra. La estatua de Coatlicue, la diosa azteca de la fertilidad que representa la síntesis de la vida y la destrucción, aparece en el cuento La fiesta brava del escritor mexicano José Emilio Pacheco. El libro sagrado de los mayas-quichés Popol Vuh fue la inspiración del escritor argentino Jorge Luis Borges para la creación de un jaguar como el motivo central de su cuento La escritura del dios. El mito de nagual - chamán que tiene la capacidad de tomar forma animal o de algún fenómeno atmosférico (lluvia, arco iris, "bola de fuego" - rayos) se encuentra incorporado en la novela El obsceno pájaro de la noche del escritor chileno José Donoso. La serpiente y el águila, dos importantes símbolos de la cultura azteca que representan la dominación de lo espiritual sobre lo material, son mencionados por el poeta chileno Pablo Neruda en su ensayo México florido y espinudo. El sincretismo, aunque no es el tema principal del opus del escritor peruano Mario Vargas Llosa, se encuentra elaborado en algunas obras suyas, como, por ejemplo, en la novela La guerra del fin del mundo, donde se describe la pervivencia de las creencias basadas en la tradición indígena precolombina, junto con el catolicismo, en la comunidad de Canudos, incluso después de su derrota (1896-1897), que ocurrió en el conflicto con el ejército brasileño. En la novela Pantaleón y las visitadoras, Vargas Llosa describe la práctica de la secta del arca que también revela muchos rasgos sincréticos, mientras que en la novela La tía Julia y el escribidor se acerca a Manco Capác, el mítico soberano y fundador del Imperio Inca. En su novela Conversación en La Catedral, Mario Vargas Llosa trata, entre otros temas, el problema del mestizaje en la sociedad peruana contemporánea. El escritor argentino Ernesto Sábato describe en su novela Sobre héroes y tumbas, paralelamente al hilo narrativo principal, la retirada del general Lavalle, héroe nacional de la Guerra de la Independencia argentina que perdura en la memoria colectiva de los indios modernos, aunque ellos provienen de los incas vencidos por los conquistadores españoles; Galović (2008: 334) explica este fenómeno por el hecho de que el general Lavalle en su caballo blanco, bañado por radiante luz, sigue estando vivo en las creencias indígenas tradicionales, basadas en la historia y el mito, como símbolo del honor, el patriotismo, la fidelidad, la esperanza y los sueños de un pueblo oprimido.

Además de los ensayos agrupados en tres partes mayores, el libro Los mayas, los aztecas y la tradición chamánica de México contiene dos textos suplementarios preparados por la autora ("Introducción”, “Epílogo: literatura y fuentes") y tres reseñas escritas por Jasmina Vrbavac, Branislav Prelević y Miodrag V. Vuković, que ofrecen evaluaciones críticas de dicha obra. Teniendo en cuenta la originalidad del tema y la exhaustividad de 
su elaboración, se puede decir que el libro Los mayas, los aztecas y la tradición chamánica de México de Jelena Galović amplió en una medida muy significativa el horizonte de expectativas de los lectores de Serbia no solamente en cuanto a las religiones precolombinas sino también en lo referente a otras prácticas espirituales de Mesoamérica.

El último libro relacionado con las religiones de la época prehispánica que apareció durante el período investigado, es la antología Los mitos y leyendas más bellos de México (Najlepši mitovi i legende Meksika) preparada por Milan Balinda (2010), publicista y periodista serbio que pasó una larga temporada (25 años) en América Latina como corresponsal del periódico Miami Herald; dicho libro fue publicado en el año 2010 por la editorial Balinda i drugovi de Belgrado, en una tirada de 500 ejemplares. Además de las (5) leyendas y los (20) mitos seleccionados de la tradición oral de los aztecas, la antología mencionada contiene también dos textos escritos por Milan Balinda, por un lado, las "Notas introductorias", que nos hablan sobre el mito y la leyenda en el mundo azteca, complementadas con breves interpretaciones de las similitudes y diferencias entre esos dos conceptos (Balinda 2010: 8-10), y, por otro, el "Epílogo", compuesto de cuatro partes, con títulos que anuncian sus contenidos ("El origen de los antiguos americanos", "Los habitantes de Mesoamérica", "Los mayas", "Los mexicas o los aztecas") y que aportan datos básicos sobre las culturas del antiguo México, descripciones cortas de las ceremonias religiosas, explicaciones breves de la importancia ritual del juego con pelota, acompañadas de las ilustraciones correspondientes (Balinda 2010: 99-105). La antología Los mitos y leyendas más bellos de México no trajo novedades sorprendentes al horizonte de expectativas de los lectores serbios, pero contribuyó a su fortalecimiento de una manera popular y accesible a todas las edades.

\section{Conclusiones}

Los resultados de la investigación llevada a cabo con el objetivo de explorar la visión que los lectores de Serbia obtuvieron sobre las religiones precolombinas a través de los libros dedicados por completo a dicho asunto, preparados por autores y editores serbios e impresos serbio, han mostrado que durante el período de veintidós años (19882010) aparecieron siete libros con esta temática, en los cuales prevalece el interés por las religiones de los mayas y los aztecas. Un avance inicial en el horizonte de expectativas ocurrió gracias al profesor Aleksandar Bošković, antropólogo, que escribió dos monografías científicas sobre 
la religión de los antiguos mayas (La religión de los mayas, 1988; La religión y la cultura de los mayas, 1990). Casi simultáneamente, o sea, a principios de los noventa del siglo pasado, el editor Miodrag Šijaković preparó dos compilaciones de varios ensayos y artículos en las cuales se tratan las mitologías y las religiones de los aztecas y los incas ( $L a$ mitología y la religión de los aztecas, 1990; La mitología y la religión de los incas, 1990). Durante la primera década del siglo XXI, el horizonte de expectativas de los lectores serbios se ensanchó mediante dos amplios estudios comparativos sobre las culturas antiguas de Mesoamérica (los mayas y los aztecas) y sus restos en la era moderna (Los grupos místicoespirituales de la actualidad, 2005; Los mayas, los aztecas y la tradición chamánica de México, 2008) escritos por la profesora Jelena Galović. Al final del período investigado, el publicista Milan Balinda preparó una selección de los mitos y las leyendas mexicanas (Los mitos y las leyendas más bellos de México, 2010). Todos los libros mencionados aparecieron en Belgrado, publicados por seis editoriales (Opus, Kodeks, Dečja knjiga, Srpski genealoški centar, Pešić i sinovi, Balinda i drugovi), con tiradas que van de 1000 a 3000 ejemplares en el siglo XX hasta 500 en el siglo XXI.

Los siete libros mencionados de autores serbios, dedicados a las religiones precolombinas e impresos en serbio, salieron a finales del siglo XX y comienzos del siglo XXI con una dinámica irregular, que está marcada por dos etapas cortas de casi simétrica frecuencia de publicación (4 libros: 1988-1990; 3 libros: 2005-2010), entre las cuales está registrada una larga pausa de 15 años (1990-2005). Sin embargo, la diversidad de los títulos publicados y el enfoque exhaustivo de los temas elaborados, habilitaron la formación de un horizonte de expectativas de alta calidad. Por lo tanto, se puede concluir que los lectores en Serbia tuvieron la oportunidad, aunque con un retraso considerable, de conocer los conceptos básicos de las religiones de los pueblos precolombinos más importantes, especialmente los mayas y los aztecas; por consiguiente, su horizonte de expectativas está bien configurado y preparado para expandirse en el futuro. Los libros sobre las religiones precolombinas, elaborados por autores y editores serbios en serbio, contribuyeron en gran medida no sólo a la modificación del horizonte de expectativas de los lectores serbios, en el sentido de su ensanchamiento y enriquecimiento, sino también influyeron significativamente en la intensificación y aumento cualitativo del intercambio cultural que se desarrolla entre varios países hispanoamericanos (sobre todo México) y Serbia. 


\section{FUENTES}

Balinda, Milan (Urednik). Najlepši mitovi i legende Meksika. Beograd: Balinda i drugovi, 2010. Štampano.

Bošković, Aleksandar. Majanska religija. Beograd: Opus, 1988. Štampano.

Bošković, Aleksandar. Religija i kultura Maja. Beograd: Kodeks, 1990. Štampano.

Galović, Jelena. Los grupos místico-espirituales de la actualidad. México: Plaza y Valdés, 2002. Impreso.

Galović, Jelena. Mistično-duhovne grupe današnjeg vremena. Beograd: Srpski genealoški centar, 2005. Štampano.

Galović, Jelena. Maje, Asteci i šamanska tradicija Meksika. Beograd: Pešić i sinovi, 2008. Štampano.

Šijaković, Miodrag (Urednik). Mitologija i religija Asteka. Beograd: Dečja knjiga, 1990a. Štampano.

Šijaković, Miodrag (Urednik). Mitologija i religija Inka. Beograd: Dečja knjiga, 1990b. Štampano.

\section{BIBLIOGRAFÍA}

Benítez, Fernando. “Prólogo”. Jelena Galović. Los grupos místico-espirituales de la actualidad, México: Plaza y Valdés, 2002: 383-384. Impreso.

Dickov, Vesna. „Odnos čovek-bog u astečkom pesništvu“. Dragan Bošković (Urednik). Srpski jezik, književnost, umetnost (Zbornik radova sa VI međunarodnog naučnog skupa održanog na Filološko-umetničkom fakultetu u Kragujevcu, 28-29. X 2011). Knj. 2, Bog, Kragujevac: Filološko-umetnički fakultet, 2012: 469-480. Štampano.

Dickov, Vesna. „Religiozna poezija Inka“. Aleksandar Prnjat \& Tijana Parezanović (Urednici). Religija u ogledalu književnosti, Beograd: Alfa univerzitet, 2013: 76-89. Štampano.

León-Portilla, Miguel. "Prólogo". Jelena Galović. Los grupos místicoespirituales de la actualidad, México: Plaza y Valdés, 2002: 5-7. Impreso.

Pavlović-Samurović, Ljiljana. Leksikon hispanoameričke književnosti. Beograd: Savremena administracija, 1993. Štampano. 


\title{
A LOOK AT PRE-COLUMBIAN RELIGIONS: THE POINT OF VIEW OF SERBIAN READERS
}

\begin{abstract}
Summary
The purpose of this work lies in investigating a peculiar aspect of the reception of pre-Columbian religions in Serbia, which consists in grouping and presenting critically, respecting the chronological criterion, the scientific studies that deal with the question of the indigenous pantheon, in addition to the compilations of the same nature, both made by Serbian authors and printed within the framework of special editions in the Serbian language. The focus is on exploring the books dedicated to the religions of the main indigenous peoples of Hispanic America (the Mayans, the Aztecs, the Incas), prepared by the different authors and editors of Serbia (anthropologists, professors of literature, researchers, journalists, critics). The attention is paid to all the parameters of this reception process (main direct participants, publishing houses, development dynamics, circulations) in order to obtain as clear and complete an image as possible about the properties of the expectations horizon of the Serbian readers (initial formation, changes, modifications, extensions) with regard to the perception and reception of the pre-Columbian religions that took place at the end of the 20th century and the beginning of the 21st century. During the period of twenty-two years (1988-2010), thanks to the Belgrade publishers, seven books appeared in various circulations (500-3000 copies), which are the result of the work of two authors (Aleksandar Bošković, Jelena Galović) and two editors (Miodrag Šijaković, Milan Balinda). Due to this successful reception process, the Serbian readers had the opportunity - though with a delay - to gain insight into the basics of religions of the most important pre-Columbian peoples, especially Mayans and Aztecs, so that their horizon of expectations is well-shaped and ready to expand in future.
\end{abstract} reception.

Keywords: pre-Columbian religions, the Incas, the Mayans, the Aztecs, 